\title{
Research with prisoners
}

\author{
After 18 months' deliberation the US Secretary of Health has responded to a report \\ questioning the ethics of research involving prisoners. Michael S. Yesley and Barbara Mishkin, \\ closely involved in the production of the report, here discuss their findings
}

UNDER American law new drugs must undergo three phases of testing before being approved by the Food and Drug Administration (FDA) for general sale. Phase 1 involves the first introduction of a drug in humans and requires testing on normal volunteers to determine the safety and general metabolic properties of the drug. Phase 2 consists of controlled clinical studies on a small number of patients to determine therapeutic efficacy. (In the United Kingdom and elsewhere, phases 1 and 2 are consolidated by testing for safety as well as efficacy on a small number of patients for whose treatment the drug is intended.) Phase 3 is similar to phase 2 but involves considerably more patients. Although no data are available by which to ascertain the extent of the use of prisoners in phase 1 tests in the United States, it is clear that they are used to a significant degree.

The reasons for the practice are partly historical. During the Second World War, civil prisoners in Illinois and New Jersey participated in research to develop treatment for malaria and other diseases that afflicted the armed forces. Such participation was considered not only acceptable but praiseworthy, for it gave inmates an opportunity to contribute to society (a form of restitution) and to enhance the war effort. Following the war, the involvement of prisoners in nontherapeutic biomedical research increased as a result of expanding government support for biomedical research and more stringent federal requirements for evaluating the safety of new drugs.

At the same time that the use of prisoners was increasing in the United States, the world was reacting to revelations of the experiments conducted in the Nazi prison camps. The Public Health Council of the Netherlands, for example, responded by specifically disapproving research involving children, old people, the insane and prisoners. The Nuremberg Code, initially drafted by an American consultant to the war crimes tribunal, is somewhat ambiguous with regard to the involvement of prisoners in research. The first principle of the Code provides that: "The voluntary consent of the human subject is essential. This means that the person involved should have legal capacity to give consent: should be so situated as

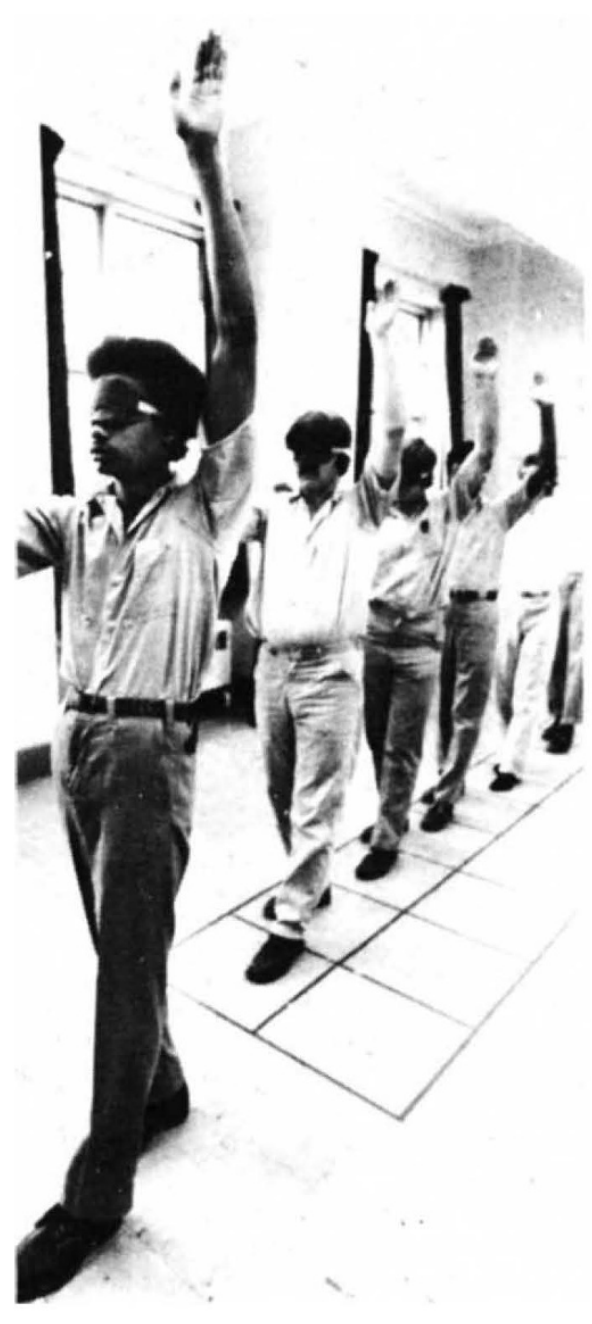

Self-confidence training at Wisconsin State Reformatory

to be able to exercise free power of choice without the intervention of any element of force, fraud, deceit, duress, overreaching, or other ulterior form of constraint or ccercion.

Many have interpreted this provision to mean that civil prisoners may not participate as research subjects, because they are not "so situated as to be able to exercise free power of choice." In the United States, however, it has been argued by the research community and by some prisoners themselves that so long as the prisoners are fully informed and no obvious duress is imposed, they may be considered free volunteers. This assertion is at the centre of the recent controversy in the United States over the participation of prisoners in research.

Jessica Mitford's book Kind and
Usual Punishment, published in 1973, was partly responsible for calling the public's attention to this issue. Mitford perceived drug research to be an exploitation precipitated by FDA drugtesting requirements and perpetuated by the economic self-interest of drug firms, investigators, prison authorities and the inmates themselves. Concurrently, academicians and civil rights organisations began to question the validity of any consent given by prisoners to participate in nontherapeutic research. They suggested that voluntary consent was impossible in penal institutions because of the poor living conditions, fear of physical violence in the cell-block, absence of good medical care and alternative ways to earn money in prison, and the obvious advantages, therefore, of leaving the general prison quariers to be paid for living in a research unit with access to individuals from the outside world. They also suggested that in a closed society such as a prison, the opportunity for exploitation is especially great when, as Mitford pointed out, prisoners are frequently prevented from reporting abuses to those on the outside.

Proponents of prison research have argued, on the other hand, that if research in prisons were to be prohibited, the result would be an inability to assure the safety of new pharmaceuticals, since prisoners are most likely to have the time and inclination to subject themselves to the kind of tests required by FDA to establish safety of new drugs. The proponents state, in addition, that phase 1 drug testing presents little risk, that injuries have been few, and that procedures are available to assure that consent is freely and knowledgeably given without undue influence or coercion.

In the midst of this debate, the National Commission for the Protection of Human Subjects of Biomedical and Behavioural Research was established by Congress to conduct studies and make recommendations in several areas of controversy involving

Drs Yesley and Mishkin are Staff Director and Assistant Staff Director, National Commission for the Protection of Human Subjects of Biomedical and Behavioral Research, Washington, D.C., but the views expressed herein are those of the authors and do not necessarily reflect those of the Commission. 
human subjects, including the participation of prisoners. The Commission set out in 1975 to investigate the validity of the various claims put forth and to examine the legal and ethical issues surrounding the participation of prisoners in research. The members of the Commission and its staff visited several prisons where research is conducted and interviewed over 250 prisoners who participate in research. The Commission conducted public hearings at which arguments for and against prison research were presented, and sponsored a conference at which the view points of minority populations were expressed. In addition, several papers and studies were prepared for the Commission on topics including the nature and extent of prisoner involvement in research in U.S. prisons; alternatives to the use of prisoners and foreign practices in drug testing; philosophical, legal and sociological perspectives on the involvement of prisoners in research; experimental behavioural practices involving prisoners; and a sociological study of research at five prisons.

The Commission found that virtually all prisoners participating in biomedical research feel that they do so freely and do not want to lose this opportunity. Most prisoners who were interviewed candidly cited financial reward as the main reason for their participation in research, and they did not appear to be motivated by the expectations of early release (which, in fact, is not granted for research participation). Further, data indicate that even in prisons where the inmate population is predominantly black, the research subjects are predominantly white, and they tend to be better educated and to hold better prison jobs than the nonparticipants. This finding contradicts the general belief that prison research exploits minority groups and those unable to obtain good prison jobs (to the extent such employment is available).

The Commission was impressed with reports of programmes that successfully use nonprisoner volunteers in phase 1 drug testing. At least one principal investigator (who formerly used prisoners for such research) reported that nonprisoner volunteers are preferable for scientific as well as social and ethical reasons. It is easier to control the subjects' abuse of drugs, for example, in a well-run research facility than in a prison. Further, he reported, the subjects become experienced in the bargaining and consent process, they are knowledgeable about the responsibilities and risks they are undertaking, and it is possible to provide commercial insurance to compensate them for any injuries that might occur.

With respect to the risks of phase 1

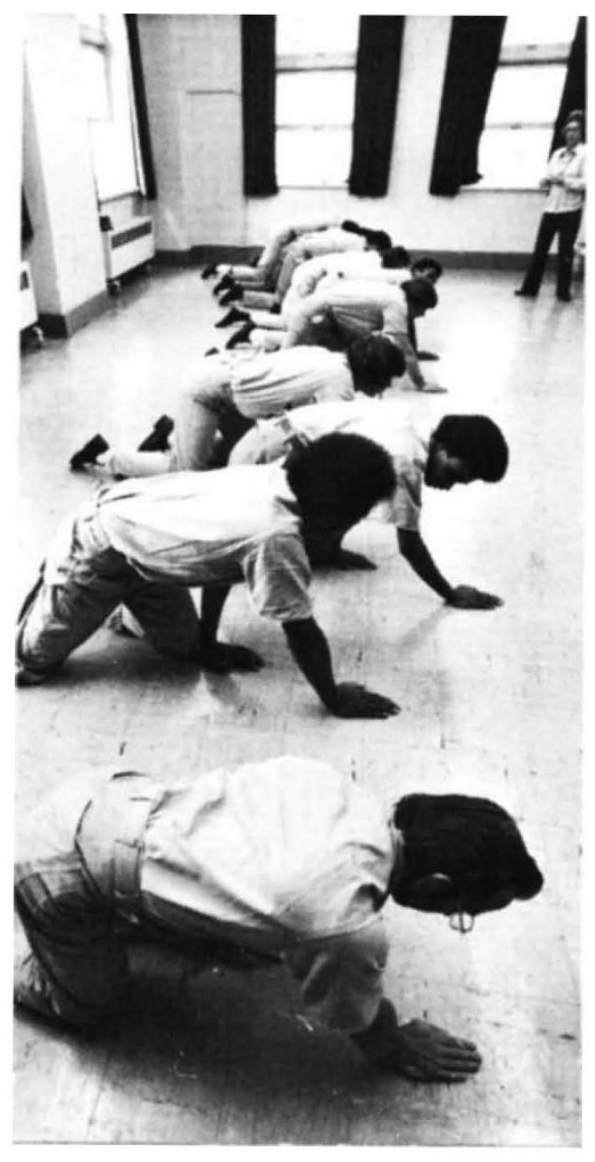

Learning to concentrate by
crawling

drug testing, it appears that they are not significant. One commercial company that provides insurance for nonprison volunteers has estimated that the risk of such "employment" is roughly equivalent to that of being a secretary.

This situation, in which the prisoners expressed their desire to participate in research, while advocates and other outside observers argued that the prisoners were unduly influenced, posed a dilemma for the members of the Commission. The irony was not lost that recognition of the limited options in prison life might be used to justify the removal of one of those options. On the other hand, it is likely that many prisoners who participate in research would choose not to do so if the conditions of prison life were substantially improved or there were optional sources of equivalent income. This likelihood may indicate undue influence, and thus involvement of prisoners in research may well constitute an exploitation.

Despite the confidence of prisoners that their participation in research was entirely voluntary, the Commissioners expressed doubts that conditions generally prevalent in United States prisons provide a setting in which voluntariness can be relied upon. The Commissioners also expressed reservations about the conduct of research in institutions that are isolated from public scrutiny and in which access to the outside is limited. The Commission concluded that the conduct of nontherapeutic research should be permitted only under acceptable prison conditions and that the burden of proof as to the social necessity of using prisoners as subjects in nontherapeutic research should be on those who wish to continue the practice.

The Commission therefore recommended to the Secretary of Health, Education, and Welfare and to Congress that the participation of prisoners in nontherapeutic research not be permitted unless any prison proposed as a site for such research is able to meet a long list of specific standards regarding health and safety conditions, job opportunities, free communication with persons on the outside, prisoner representation on research review boards, and the right of prisoners to form effective grievance committees. In addition, any investigator proposing to use prisoners in such a facility must demonstrate that the need to use prisoners in a particular research project is compelling and that such use would not result in social inequity.

The Commission recommended, however, that research designed to improve understanding about the causes of deviant behaviour, the effects of incarceration, and the factors related to parole performance and recidivism be permitted, so long as certain procedures are followed to protect the rights of prisoners, to safeguard their privacy and to preserve the confidentiality of the data obtained.

The Commission's recommendations* were submitted to the Secretary of Health, Education and Welfare in October 1976. After a delay occasioned by disagreement in the department over the wisdom of implementing the recommendations, Secretary Joseph Califano, Jr., announced last month that he would issue regulations even stricter than those recommended by the Commission for nontherapeutic research with more than minimal risk (e.g., phase 1 drug testing). In fact, he proposed to ban the participation of prisoners in such research under any conditions. The Secretary's stated grounds for his decision espoused the arguments of civil rights advocates that prisoners, by the nature of their situation, are incapable of giving informed consent.

*Copies of the Commission's report and recommendations may be obtained by writing to: Public Information Officer, National Commission for the Protection of Human Subjects, Room 125, 5333 Westbard Avenue, Bethesda, Maryland 20016. 